Картофелеводство: болезни и защита растений

\title{
РАЗРАБОТКА НОВЫХ СИСТЕМ ПЦР-ИДЕНТИФИКАЦИИ НЕКАРАНТИННЫХ ПАТОГЕНОВ КАРТОФЕЛЯ (Solanum tuberosum L.), РАСПРОСТРАНЕННЫХ НА ТЕРРИТОРИИ РОССИИ*
}

\author{
А.А. СТАХЕЕВ1, М.С. ЧИГАРЁВА' ${ }^{1}$ А.И. УСКОВ², И.В. ШМЫГЛЯ 2 , \\ Ю.А. ВАРИЦЕВ 2 , П.А. ГАЛУШКА², С.К. ЗАВРИЕВ1
}

Российская Федерация - один из крупнейших производителей картофеля в мире: за 2018 год посевные площади этой культуры на территории страны составили 310,7 тыс. га, а валовые сборы в промышленном секторе - 7157 тыс. т. Однако для современного картофелеводства характерно прогрессивное распространение вирусных болезней и бактериозов, приводящих к снижению урожая и катастрофическому ухудшению стандартного качества клубней. В настоящее время в картофелеводстве широко применяются классические методы диагностики, в частности растения-индикаторы, серологические и цитологические подходы. Они относительно надежны, но не всегда достаточно чувствительны, требуют высокой квалификации персонала и существенных затрат времени. Современной альтернативой этим методам служат диагностические системы на основе полимеразной цепной реакции (ПЦР), в частности ее модификации в формате реального времени (количественная ПЦР). В представленном исследовании для шести некарантинных патогенов (некротических штаммов Y вируса картофеля PVYN-NTN и PVYN:o, вируса погремковости табака, патогенных бактерий Dickeya solani, D. dianthicola, Pectobacterium atrosepticum) впервые в России были разработаны системы диагностики и идентификации в формате количественной ПЦР. Праймеры и флуоресцентно меченные зонды подбирали на основе последовательностей нуклеотидов, представленных в международной базе данных NCBI GenBank, с учетом размера ампликона не более 500 п.н. Специфичность предложенных систем была показана в тестах с генетическим материалом патогенов, таксономически близких или занимающих сходные экологические ниши: ординарный штамм PVY, вирус метельчатости верхушки картофеля, бактерии Pectobacterium carotovorum, D. zeae. Качество работы предложенных тест-систем также оценивали с использованием растительного материала, предположительно зараженного анализируемыми патогенами. Выделение нуклеиновых кислот осуществляли с использованием комплектов реактивов Проба-НК (для РНК) и Проба-ГС (для ДНК) (ООО «АгроДиагностика», Россия). Для проведения реакции обратной транскрипции использовали набор RevertAid Premium First Strand cDNA Synthesis Kit («Thermo Scientific», США). ПЦР проводили в амплификаторе Терцик («ДНК-технология», Россия), количественную ПЦР - в детектирующем амплификаторе ДТ-96 («ДНК-технология», Россия). Для оценки возможного ингибирования в реакционную смесь добавляли внутренний контрольный образец (ВКО), представляющий собой плазмиду со специфической вставкой (размер 560 п.н.). Положительные контрольные образцы (ПКО) клонировали с использованием набора Quick-TA kit («Евроген», Россия). Концентрацию плазмидной ДНК определяли с помощью спектрофотометра NanoVue («GE HealthCare», США). Секвенирование молекул ДНК проводили на автоматическом секвенаторе ABI PRISM 3730 («Applied Biosystems», США). Аналитическую чувствительность оценивали с использованием количественной ПЦР, при которой в качестве матрицы выступали последовательные 10-кратные разведения плазмидных ДНК (ПКО в четырех независимых повторностях) в диапазоне от $10^{7}$ до $10^{0}$ копий на реакцию. Была показана высокая чувствительность разработанных тест-систем, составившая от 10 до 500 копий специфической ДНК на реакцию, а также высокая воспроизводимость $(C v)$ 1,5-2,0 \%). Максимальное разгорание разработанных гидролизуемых зондов составило от 1200 до 2000 ед. фона. Универсальность предложенных профилей амплификации может послужить основой для адаптации тест-систем в формат мультиплексной ПЦР. Совокупность полученных результатов свидетельствует о том, что разработанные системы с высокой специфичностью и чувствительностью детектируют анализируемые патогены и могут быть использованы в рамках мероприятий по фитосанитарному контролю и рутинной диагностике шести некарантинных патогенов в растениях, посадочном материале и пищевой продукции.

Ключевые слова: диагностика, количественная ПЦР, чувствительность, специфичность, Pectobacterium atrosepticum, Dickeya solani, Dickeya dianthicola, некротические штаммы Ү вируса картофеля, PVY, вирус погремковости табака.

Картофель - одна из основных сельскохозяйственных культур с общемировым объемом производства около 375 млн т. Существенным

* Статья подготовлена в рамках ФНТП развития сельского хозяйства РФ на 2017-2025 годы (подпрограмма «Развитие селекции и семеноводства картофеля в Российской Федерации»). 
фактором, снижающим количество и качество получаемого картофеля, становятся болезни, вызываемые фитопатогенами различной природы, относящимися к разным таксономическим группам: ежегодные потери, связанные с вирозами, составляют 7 \% от урожая, с микозами и бактериозами $-14 \%(1,2)$. В настоящее время известно свыше 50 возбудителей вирусных и бактериальных болезней, выявленных на картофеле в регионах с разнообразными природно-климатическими условиями $(3,4)$. Вместе с тем при сертификации семенного картофеля в России контролируются лишь некоторые из них, а интегрированная система мониторинга вирусных и бактериальных заболеваний этой культуры отсутствует $(5,6)$.

Для современного картофелеводства характерно прогрессивное распространение вирусных болезней некротической кольцевой пятнистости клубней и пестростебельности, а также бактериоза черной ножки картофеля, вызывающих, помимо снижения урожая, катастрофическое ухудшение стандартного качества клубней, что становится серьезной проблемой для товарного производства (7).

Кольцевой некроз клубней картофеля (КНКК, образование на клубнях колец и дуг темно-коричневого цвета) вызывают некротические штаммы Y-вируса (potato virus Y, PVYN-NTN). В то же время идентифицированы вызывающие КНКК изоляты, которые обладают серологическими свойствами, характерными для ординарного штамма Y-вируса картофеля (PVYO). Эти штаммы, выделенные в Европе, отнесены к подгруппе PVYN-Wilga некротических штаммов (по названию сорта, на котором впервые выявлен вирус с подобными свойствами) (8-10). Группа изолятов PVY с аналогичными свойствами, обнаруженных позднее в Северной Америке, получила обозначение PVYN:O (11). Геном PVY представляет собой одноцепочечную РНК длиной около 9700 п.н. На сегодняшний день для всех перечисленных групп изолятов определены структуры полных геномов и их полиморфизм, что значительно упрощает исследования и разработку систем диагностики (12). Пестростебельность картофеля, которая проявляется образованием некротических дуг и пятен как на поверхности клубня, так и внутри паренхимной ткани, вызывается вирусом погремковости табака (tobacco rattle virus, TRV, раттл-вирус), распространяемым почвенными нематодами отряда Dorylaimida рода Trichodorus $(13,14)$.

По данным Лаборатории фитопаразитологии ЦПИПЭ РАН, которая ведет изучение распространения нематод-триходорид, в 75 \% образцов растений, зараженных триходоридами, обнаруживается раттл-вирус (15). TRV относится к типичным патогенам природно-очаговых заболеваний. Уже в первый год попадания здорового растения картофеля в инфекционный очаг урожай клубней становится нетоварным $(16,17)$. Вызываемая вирусом болезнь описана во многих странах, а в середине 1970-х годов выявлена на территории бывшего СССР (16). Вирус широко представлен в Нидерландах, Германии, Бельгии, Англии, Франции, Польше, Швеции, Австрии, Финляндии, США, Японии, странах Балтии и России (18-20). Идентификация TRV затруднена, поскольку во многих случаях наблюдается смешанная инфекция $(15,17)$. Геном TRV состоит из линейной одноцепочечной РНК и включает две части - PHК-1 и РНК-2, общий размер - от 9000 до 11500 п.н. (21). В настоящее время расшифровано значительное количество структур полных геномов этого вируса для изолятов различного географического происхождения $(22,23)$.

Распространение бактериоза черной ножки картофеля за последние годы заметно прогрессирует. Выявлен ряд новых возбудителей, вызывающих водянистую гниль стеблей и мягкие гнили клубней (24). Симпто- 
мы поражения клубней и растений картофеля бактериями рода Dickeya spp. во многом сходны с симптомами при заражении бактериями рода Pectobacterium spp. (25). Вместе с тем виды Dickeya spp. могут вызывать болезнь при наличии небольшого количества инфекционного агента, легче распространяются по сосудистым тканям растений, агрессивнее, а при повышенной температуре поражение мокрой гнилью сильнее, чем в случае инфицирования Pectobacterium atroseptica. Для Dickeya spp. характерно распространение в регионах с жарким климатом, однако в связи с локальными изменениями климатических условий отмечено их продвижение в регионы с умеренным климатом, традиционные для производства картофеля. Важным этапом в исследованиях этих бактериальных патогенов стала расшифровка структур полных геномов (26-28).

Основной способ радикальной борьбы с вирусными и бактериальными болезнями картофеля заключается в выявлении возбудителей заболеваний на ранних этапах семеноводства с последующей выбраковкой инфицированного материала. Классические методы диагностики надежны, однако зачастую не обладают достаточной чувствительностью, а также требуют высокой квалификации персонала и существенных затрат времени (29). В связи с этим необходимы новые отечественные ПЦР тест-системы для выявления патогенов, ухудшающих качество товарного картофеля и наносящих значительный экономический ущерб.

В настоящем исследовании для шести некарантинных патогенов (некротических штаммов Y вируса картофеля PVYN-NTN и PVYN:O, вируса погремковости табака, патогенных бактерий Dickeya solani, Dickeya dianthicola, Pectobacterium atrosepticum) впервые в России были разработаны системы диагностики и идентификации в формате количественной ПЦР.

Цель работы - создание оригинальных отечественных систем для идентификации некарантинных патогенов картофеля на основании количественной полимеразной цепной реакции, оценка чувствительности и эффективности этих систем, а также возможности их применения в практике фитопатологического анализа.

Методика. Исследовали выделенные и поддерживаемые во Всероссийском НИИ картофельного хозяйства имени А.Г. Лорха (ВНИИКХ) образцы фитопатогенов: PVYNTN, PVYN:O, TRV, Pectobacterium atrosepticum, Dickeya solani, Dickeya dianthicola. Кроме того, были использованы образцы фитопатогенов, близких в таксономическом отношении либо сходных по симптоматике при заражении растений картофеля: PVY (potato virus Y, обычный штамм), вирус метельчатости верхушки картофеля (potato mop top virus, PVTV), Pectobacterium carotovorum, Dickeya zeae. Эти образцы выделяли при тестировании семенного материала, поступающего из Центрального и Южного федеральных округов Российской Федерации. Для оценки использовали моноклональные антитела фирмы «Bioreba» (Швейцария). Кроме того, предложенные тест-системы были апробированы на генетическом материале 9 образцов клубней картофеля (Solanum tuberosum L.) различных сортов из Московской области, предположительно зараженных анализируемыми патогенами.

Нуклеиновые кислоты выделяли с использованием комплектов реактивов Проба-НК (для РНК) и Проба-ГС (для ДНК) (ООО «АгроДиагностика», Россия) в соответствии с протоколом производителя. Для проведения реакции обратной транскрипции использовали набор RevertAid Premium First Strand cDNA Synthesis Kit («Thermo Scientific», США).

Дизайн праймеров и флуоресцентно меченных зондов выполняли с помощью выравнивания последовательностей нуклеотидов ряда локусов де- 
тектируемых организмов, депонированных в базе данных National Center for Biotechnology Information (GenBank, https://www.ncbi.nlm.nih.gov/genbank/). Для выравнивания использовали алгоритм ClustalW (30). Подбор и оценку физико-химических свойств олигонуклеотидов осуществляли в программе Oligo v. 6.71 (https://www.oligo.net/oligo_updates.htm).

ПЦР проводили в амплификаторе Терцик («ДНК-технология», Россия) в соответствии со следующими программами: для пар праймеров Y-NTN(F-R), Y-NW(F-R), TRV(F-R), Dsol(F-R) - 90 с при $93{ }^{\circ} \mathrm{C} ; 20$ с при $93{ }^{\circ} \mathrm{C}, 5$ с при $64{ }^{\circ} \mathrm{C}, 5$ с при $67{ }^{\circ} \mathrm{C}$ (5 циклов); 1 с при $93{ }^{\circ} \mathrm{C}, 5$ с при $64{ }^{\circ} \mathrm{C}, 5$ с при $67{ }^{\circ} \mathrm{C}$ (40 циклов); для $\operatorname{Patr}(\mathrm{F}-\mathrm{R})$, Ddi(F-R) - 90 с при $93{ }^{\circ} \mathrm{C}$; 20 с при $93{ }^{\circ} \mathrm{C}, 5$ с при $64{ }^{\circ} \mathrm{C}, 5$ с при $67{ }^{\circ} \mathrm{C}(5$ циклов); 1 с при $93{ }^{\circ} \mathrm{C}, 5$ с при $60{ }^{\circ} \mathrm{C}$ (40 циклов). Количественную ПЦР осуществляли в детектирующем амплификаторе ДТ-96 («ДНК-технология», Россия) по аналогичным программам амплификации. Для анализа полученных результатов использовался пороговый метод (31). Каждый из образцов ДНК был протестирован в трех повторностях. Состав ПЦР-буфера и методика разделения продуктов амплификации с помощью гель-электрофореза описаны в более ранних публикациях $(32,33)$.

Для оценки возможного ингибирования в реакционную смесь добавляли внутренний контрольный образец (BKO), представляющий собой плазмиду pTZ57R/T со специфической вставкой (размер 560 п.н.), то есть реакция происходила в мультиплексном формате. Положительные контрольные образцы (ПКО) клонировали с использованием набора Quick-TA kit («Евроген», Россия) по протоколу производителя. Концентрацию плазмидной ДНК определяли с помощью спектрофотометра NanoVue («GE Healthcare», США). Секвенирование молекул ДНК проводили в ЗАО «Евроген», используя набор реактивов ABI PRISM BigDye Terminator v. 3.1 («Applied Biosystems», США), с последующим анализом продуктов реакции на автоматическом секвенаторе ABI PRISM 3730 («Applied Biosystems», США).

Аналитическую чувствительность оценивали в количественной ПЦР с последовательными 10-кратными разведениями плазмидных ДНК в качестве матрицы (ПКО в четырех независимых повторностях) в диапазоне от $10^{7}$ до $10^{0}$ (единичные копии) копий на реакцию. Для каждого ПКО строили график линейной зависимости порогового цикла от числа копий специфической ДНК в реакции.

Для оценки воспроизводимости использовали стандартные отклонения $\pm \mathrm{SD}$, вычисленные с учетом усредненного значения $\mathrm{C}_{\mathrm{q}}$ для серии разведений. Вариабельность значений $\mathrm{C}_{\mathrm{q}}$ оценивали с помощью тестирования каждого разведения три раза в трех повторностях. Также вычисляли коэффициенты вариации $(C v, \%)$.

Результаты. На основании анализа последовательностей нуклеотидов, представленных в GenBank для анализируемых патогенов, для дизайна праймеров и зондов мы выбрали следующие локусы: для PVYNTN - ген белка оболочки (GU980964, AF321554, AJ535662, GU550076, AJ315774), для PVYN:0 - ген VPg (EF638893, EF638901, EF638902-638892), для TRV ген РНК-зависимой РНК полимеразы (JX267264-267270, MF918561-918567), для D. dianthicola - ген б-фактора PHK полимеразы (rpoD, MH118541, LC275948-275957). Для остальных патогенов использовали маркерные фрагменты последовательностей полных геномов: P. atrosepticum (СР024956, CР009125, СР007744), D. solani (СР024710, СР017453, СР016928). При подборе праймеров выравнивали соответствующие локусы целевых патогенов и близкородственных таксонов. Также принимали во внимание желательную температуру отжига праймеров не ниже $60{ }^{\circ} \mathrm{C}$. В итоге 4 пары прай- 
меров имели расчетную температуру отжига $64{ }^{\circ} \mathrm{C}, 2$ пары $-60{ }^{\circ} \mathrm{C}$. Структура и свойства разработанных праймеров, а также размеры продуктов амплификации приведены в таблице 1.

1. Характеристика праймеров, разработанных для идентификации шести некарантинных патогенов картофеля (Solanum tuberosum L.)

\begin{tabular}{|c|c|c|c|}
\hline Патоген & Нуклеотидная последовательность 5' $\rightarrow 3^{\prime}$ & $\mathrm{T}_{\mathrm{o}},{ }^{\circ} \mathrm{C}$ & $\begin{array}{l}\text { Размер амплико- } \\
\text { на, п.н. }\end{array}$ \\
\hline$\overline{\text { PVYNTN }}$ & $\begin{array}{l}\text { Y-NTNF: TGAAACCAATCGTTGAGAAACA } \\
\text { Y-NTNR: GTACTGATGCCACCGTCGT }\end{array}$ & 60 & 290 \\
\hline PVYN:0 & $\begin{array}{l}\text { Y-N0F: CAAGTCAAGCAGGAGGTTTG } \\
\text { Y-N0R: CCCAGTCTGCCTTAGTTTA }\end{array}$ & 60 & 350 \\
\hline TRV & $\begin{array}{l}\text { TRVF: TTTCTTACATTCATGACTGGCT } \\
\text { TRVR: TTGACCAACTCTCGCGGTAC }\end{array}$ & 60 & 320 \\
\hline Pectobacterium atrosepticum & $\begin{array}{l}\text { PatrF: CAGTAGGTTTGGGAGCAGCC } \\
\text { PatrR: CCACTACCGATGATGCTCCC }\end{array}$ & 64 & 280 \\
\hline Dickeya solani & $\begin{array}{l}\text { DsolF: ATGTACTAATCAGACATGTTGCTT } \\
\text { DsolR: TGTATCCTGATTAATTTGTGATCC }\end{array}$ & 60 & 200 \\
\hline D.dianthicola & $\begin{array}{l}\text { DdiF: TGTCCGATTTGATCACCGT } \\
\text { DdiR: ATGCTGTTGTCATCATCGGAC }\end{array}$ & 64 & 160 \\
\hline
\end{tabular}

П р и м е ч а н и е. PVYNTN - Y вирус картофеля (штамм NTN), PVYN:0 - Y вирус картофеля (штамм $\mathrm{N}: 0)$, TRV - вирус погремковости табака; $\mathrm{T}_{\mathrm{o}}$ - расчетная температура отжига праймеров.

Для оценки специфичности разработанных праймеров, помимо ДНК или кДНК анализируемых патогенов, использовали генетический материал близкородственных или занимающих сходные экологические ниши организмов, таких как обычный штамм PVY, вирус метельчатости верхушки картофеля (PVTV), бактерии Pectobacterium carotovotum, Dickeya zeae. Электрофоретический анализ продуктов амплификации показал, что все использованные пары праймеров строго специфичны. В дальнейшем это был анализ в формате количественной ПЦР (табл. 2).

2. Тестирование специфичности праймеров, разработанных для идентификации шести некарантинных патогенов картофеля (Solanum tuberosum L.) методом количественной ПЦР

\begin{tabular}{|c|c|c|c|c|c|c|}
\hline \multirow{2}{*}{ Патоген } & \multicolumn{6}{|c|}{ Праймер } \\
\hline & Y-NTNF-R & Y-NOF-R & TRVF-R & PatrF-R & DsolF-R & DdiF-R \\
\hline PVYNTN & $+(29,1)$ & - & - & - & - & - \\
\hline PVYN:0 & - & - & _- & - & - & - \\
\hline PVY & - & - & - & - & - & - \\
\hline TRV & - & - & $+(24,1)$ & - & - & - \\
\hline PVTV & - & - & - & - & - & - \\
\hline Pectobacterium atrosepticum & - & - & - & $+(25,3)$ & - & - \\
\hline P. carotovorum & - & - & - & - & - & - \\
\hline Dickeya solani & - & - & - & - & $+(27,4)$ & - \\
\hline D. dianthicola & - & - & - & - & - & $+(29,3)$ \\
\hline D. zeae & - & - & - & - & - & - \\
\hline $\begin{array}{l}\text { П р и м е ч а н и е. PVY } \\
\text { PVY (штамм N:0), TRV } \\
\text { ля. В скобках приведены } \\
\text { ный результат, «-»- отри }\end{array}$ & $\begin{array}{l}\text { - Ү вирус карт } \\
\text { - вирус погре } \\
\text { средние знач } \\
\text { ицательный ре }\end{array}$ & $\begin{array}{l}\text { офеля (обыч } \\
\text { мковости таб } \\
\text { ения порогов } \\
\text { езультат. }\end{array}$ & $\begin{array}{l}\text { й штамм) } \\
\text { а, РVTV } \\
\text { циклов г }\end{array}$ & $\begin{array}{l}\mathrm{Y}^{\mathrm{NTN}}- \\
\text { грус мете. } \\
\text { еем повто }\end{array}$ & $\begin{array}{l}\text { (штамм } 1 \\
\text { ости вер } \\
\text { тям; «+» }\end{array}$ & $\begin{array}{l}\text {, PVYN:0 } \\
\text { й картоф } \\
\text { оложитель }\end{array}$ \\
\hline
\end{tabular}

3. Зонды и аналитическая чувствительность тест-систем, разработанных для идентификации шести некарантинных патогенов картофеля (Solanum tuberosum L.) методом количественной ПЦР

\begin{tabular}{|c|c|c|c|}
\hline Патоген & Нуклеотидная последовательность зонда 5' $\rightarrow 3^{\prime}$ & $\mathrm{T}_{\mathrm{O}},{ }^{\circ} \mathrm{C}$ & $\begin{array}{l}\text { Чувствительность, } \\
\text { число копий ДНК } \\
\text { на реакцию }\end{array}$ \\
\hline PVYNTN & (BHQ1)-TGCGGCCTTCAT(FAMdT)TGAATGTGCGC & 82 & $1 \times 10^{1}$ \\
\hline PVYN:0 & (BHQ1)-GCAAGCCTTGGGCAG(FAMdT)AACACGACCA & 81 & $1 \times 10^{2}$ \\
\hline TRV & (BHQ1)-GAACCGTGGCAGG(FAMdT)GAGAGGAGACAC & 82 & $1 \times 10^{2}$ \\
\hline Pectobacterium & & & \\
\hline atrosepticum & (BHQ1)-CGCGTCTTTTTT(FAMdT)GGGGTGTCGGCA & 83 & $5 \times 10^{2}$ \\
\hline Dickeya solani & (BHQ1)-CGACGTGAAAATGTGA(FAMdT)GACTTCCATCC & 82 & $5 \times 10^{1}$ \\
\hline D. dianthicola & (BHQ1)-TTCGTCTTCTTCGC(FAMdT)TTCGTCGTCGTCA & 82 & $1 \times 10^{1}$ \\
\hline
\end{tabular}

П р и м е ч а и е. PVYNTN - Y вирус картофеля (штамм NTN), PVYN:0 - Y вирус картофеля (штамм $\mathrm{N}: 0)$, TRV - вирус погремковости табака; $\mathrm{T}_{\mathrm{o}}-$ расчетная температура отжига зондов. 
Другой важный показатель качества работы диагностической системы - ее аналитическая чувствительность, для определения которой использовали 10-кратные разведения плазмид (ПКО) с известными концентрациями и числом копий в реакционной смеси. Наибольшей чувствительностью обладали системы идентификации PVYNTN и D. dianthicola (около 10 копий плазмиды с соответствующим клонированным фрагментом ДНК на реакцию), наименее чувствительной из всех была система идентификации P. atrosepticum (500 копий на реакцию) (табл. 3).

Диапазон значений эффективности для разработанных тест-систем колебался от 91,2 до 98,0 \%. Значения стандартных отклонений при тестировании каждого из 10-кратных разведений в трех повторностях варьировали от 0,09 до 0,53 , величина $C v$ не превышала $2 \%$. На рисунке 1 в качестве примера приведены графики зависимости порогового цикла от числа копий плазмид с клонированными фрагментами ДНК целевых объектов (ПКО) на одну реакцию, а также графики накопления флуоресцентного сигнала на примере тест-систем для $\mathrm{PVY}^{\mathrm{NTN}}$ и D. dianthicola.

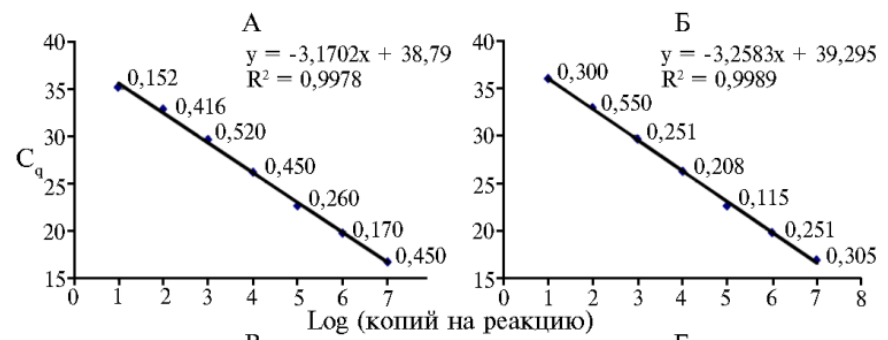

B

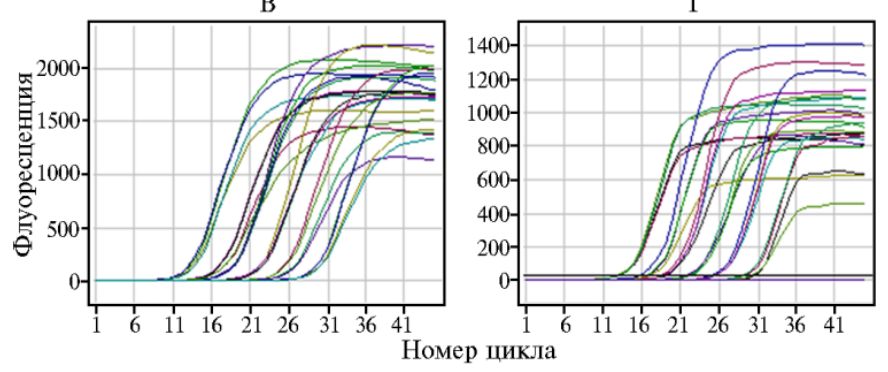

Рис. 1. Оценка чувствительности и эффективности тест-систем, разработанных для идентификации шести некарантинных патогенов картофеля (Solanum tuberosum L.), со специфическими положительными контролями в 10-кратных разведениях: А и Б - зависимость порогового цикла количественной ПЦР от числа копий плазмидной ДНК на реакцию (рядом с каждой точкой показаны значения стандартных отклонений, вычисленные для четырех повторностей), В и Г - соответствующие графики накопления флуоресценции. Чувствительность тест-системы для PVYNTN - 10 копий на реакцию при эффективности 98,0 \% (A), для Dickeya dianthicola - 10 копий на реакцию при эффективности 96,7% (Б).

Качество предложенных тест-систем также оценили с использованием клубней картофеля разных сортов, предположительно зараженных анализируемыми патогенами. При постановке ПЦР, помимо специфических праймеров и зондов, в реакционную смесь добавляли плазмиду ВКО, соответствующую пару праймеров и зонд. У всех девяти образцов картофеля на электрофореграммах продуктов ПЦР кДНК/ДНК с парами праймеров, специфичными в отношении PVYNTN и D. dianthicola, присутствовала полоса, соответствующая продукту амплификации ВКО, что указывает на отсутствие ингибирования реакции (рис. 2). В свою очередь, отсутствие специфической полосы в пробирках отрицательного контроля свидетельствует об отсутствии контаминации рабочей зоны специфическими ампликонами. Как следует из представленных электрофореграмм, кДНК 
вируса PVYNTN присутствовала в образцах №№ 3 (сорт Ред Скарлетт), 4 (сорт Жуковский ранний), 7 (сорт Фаворит III), 8 (сорт Помдор), 9 (сорт Флорис), а ДНК D. dianthicola - в образцах №№ 2 (сорт Ред Скарлетт), 3 (сорт Ред Скарлетт), 6 (сорт Романо), 8 (сорт Помдор), 9 (сорт Флорис).
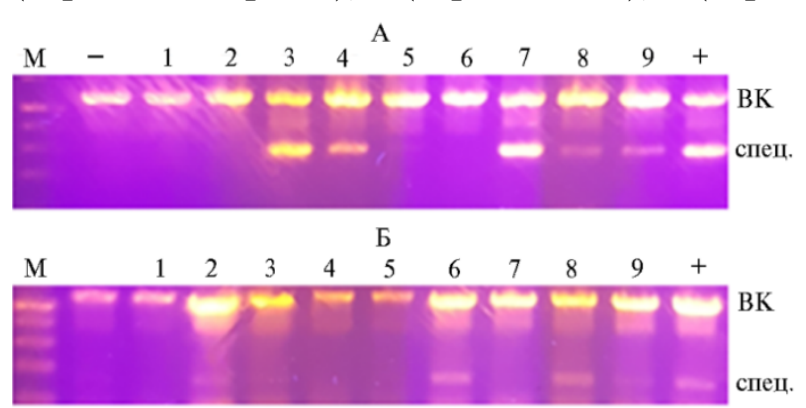

Рис. 2. Электрофореграммы продуктов ПЦР-амплификации (А - кДНК, Б - ДНК) при тестировании клубней картофеля, предположительно зараженных некарантинными патогенами, с парами праймеров Y-NTNF-R (A) и DdiF-R (Б). ВK - внутренний контрольный образец, спец. - специфический продукт амплификации; 1, 2, 3 - сорт Ред Скарлет, 4 - сорт Жуковский ранний, 5, 6 - сорт Романо, М - маркер молекулярных масс; «-» - отрицательный контрольный образец, «+» - положительный контрольный образец.

Отметим, что в литературе в настоящее время описаны несколько вариантов тест-систем для идентификации патогенов, изучаемых в настоящей работе. В.К. Швидченко с соавт. (34) показали, что метод ПЦР в реальном времени существенно более специфичен, чем ИФА, при диагностике вирусов картофеля, в том числе PVY (диагностическая чувствительность ИФА относительно ПЦР-РВ - 68 \%). Предложен ряд систем в формате мультиплексной ПЦР, в частности для определения некротических штаммов $\mathrm{PVY}^{\mathrm{N}: 0}$ и $\mathrm{PVY}^{\mathrm{NTN}}$ (35), а также основных пектинолитических бактерий, включая $P$. atrosepticum и Dickeya spp. (минимальная чувствительность - 0,01 нг/мкл специфической ДНК) (36), однако они не были адаптированы в формат количественной ПЦР. Праймеры, позволяющие специфично различать виды рода Dickeya, были описаны в 2013 году (37) и успешно использованы при выявлении патогенов в овощных культурах на территории Северной Ирландии (38). Для такой тест-системы показана очень высокая чувствительность, составившая около 0,05 пг ДНК на реакцию (около 10 копий плазмидной ДНК). Также, описан ряд систем диагностики вируса погремковости табака разной чувствительности (39-41). В работе R. Holeva с соавт. (42) чувствительность системы составила около 1 фг плазмидной ДНК на реакцию (приблизительно $10^{2}$ копий).

Таким образом, основные характеристики предложенных тестсистем оказались близки к таковым у наиболее эффективных зарубежных аналогов или даже превосходили их. Чувствительность систем составила от 10 до 500 копий специфической ДНК на реакцию, а эффективность амплификации превышала 90 \%. Показана высокая воспроизводимость получаемых результатов ( $C v$ не более $2 \%$, стандартные отклонения по разведениям - не более 0,53 ). Отмечена высокая степень разгорания специфических зондов, а также оптимизирована система внутреннего контроля. Качество работы тест-систем подтверждено тестами с использованием растительного материала, зараженного исследуемыми патогенами. Совокупность полученных результатов свидетельствует о том, что разработанные тест-системы с высокой чувствительностью и специфичностью идентифицируют шесть некарантинных патогенов картофеля, наносящих существенный экономический ущерб. Эти системы могут стать важным компонентном мониторинга зараженности посадочного материала, растений и пищевой продукции фитопатогенами. 
1. Oerke E.-C. Crop losses to pests. The Journal of Agricultural Science, 2006, 144(1): 31-43 (doi: 10.1017/S0021859605005708).

2. Malko A., Frantsuzov P., Nikitin M., Statsyuk N., Dzhavakhiya V., Golikov A. Potato pathogens in Russia's regions: an instrumental survey with the use of real-time PCR/RT-PCR in matrix format. Pathogens, 2019, 8(1): 18 (doi: 10.3390/pathogens8010018).

3. Говоров Д.Н., Живых А.В., Новоселов Е.С., Голиков А.Г. Мониторинг бактериальных и вирусных болезней сельскохозяйственных культур. Защита и карантин растений, 2015, 7: 35-37.

4. Шляхов В.А., Григорян Л.Н. Идентификация вирусных болезней картофеля методом ПЦР-диагностики на территории Астраханской области. Живые и биокосные системы, 2017, 21: 6 .

5. ГОСТ 33996-2016. Картофель семенной. Технические условия и методы определения качества. М., 2017.

6. Gera A., Marco S. Detection and identification of viruses in potatoes. In: Virus and virus-like diseases of potato and production of seed-potatoes /G. Loebenstein, P.H. Berger, A.A. Brunt, R.H. Lawson (eds.). Springer, Dordrecht, 2000: 271-283 (doi: 10.1007/978-94-007-0842-6).

7. Анисимов Б.В., Белов Г.Л., Варицев Ю.А., Еланский С.Н., Журомский Г.К., Завриев С.К., Зейрук В.Н., Иванюк В.Г., Кузнецова М.А., Пляхневич М.П., Пшеченков К.А., Симаков Е.А., Склярова Н.П., Сташевски 3., Усков А.И., Яшина И.М. Защита картофеля от болезней, вредителей и сорняков. М., 2009.

8. Chrzanowska M. New isolates of the necrotic strain of potato virus $Y(P V Y N)$ found recently in Poland (doi: 10.1007/BF02358039).

9. Visser J.C., Bellstedt D.U., Pirie M.D. The recent recombinant evolution of a major crop pathogen potato virus Y. PLoS ONE, 2012, 7(11): e50631 (doi: 10.1371/journal.pone.0050631).

10. Ribeiro S.R.R.P., Pinto C.A.B.P, Costa S.B.F.G., Menezes M., dos Reis Figueira A.R. Resistance of potato clones to necrotic recombinant strains of potato virus Y (PVY). Ciência e Agrotecnologia, 2014, 38(4): 343-351 (doi: 10.1590/S1413-70542014000400004).

11. Dougherty W.G., Carrington J.C. Expression and function of polyviral gene products. Annual Review of Phytopathology, 1988, 26: 123-143 (doi: 10.1146/annurev.py.26.090188.001011).

12. Hu X., Karasev A.V., Brown C.J., Lorenzen J.H. Sequence characteristics of potato virus Y recombinants. Journal of General Virology, 2009, 90(12): 3033-3041 (doi: 10.1099/vir.0.014142-0).

13. Козырева Н.И., Романенко Н.Д. Распространение нематод семейства Trichodoridae переносчиков тобравирусов в Московской области. Паразитология, 2008, 42(5): 428-434.

14. Romanenko N.D., Kozireva N.I. Investigations of trichodorid nematodes (Nematoda: Trichodoridae) and tobraviruses in Russia. Russian Journal of Nematology, 1998, 6(1): 77.

15. Kozyreva N.I. The distribution of tobacco rattle virus and trichodorid nematodes in potato fields of the Moscow region. Russian Journal of Nematology, 2001, 2: 150.

16. Ларина Э.И., Теплоухова Т.Н. Вирус погремковости табака. Защита растений, 1975, 3: 51.

17. Рогозина Е.В., Мироненко Н.В., Афанасенко О.С., Мацухито Ю. Широко распространенные и потенциально опасные для российского агропроизводства возбудители вирусных болезней картофеля. Вестник защиты растений, 2016, 4(90): 24-33.

18. Cooper J.I. The distribution in Scotland of tobacco rattle virus and its nematode vectors in relation to soil type. Plant Pathology, 1971, 20(2): 51-58 (doi: 10.1111/j.1365-3059.1971.tb00510.x).

19. Beuch U., Persson P., Edin E., Kvarnheden A. Necrotic diseases caused by viruses in Swedish potato tubers. Plant Pathology, 2014, 63(3): 667-674 (doi: 10.1111/ppa.12141).

20. Yellareddygari S.K.R., Brown C.R., Whitworth J.L., Quick R.A., Hamlin L.L., Gudmestad N.C. Assessing potato cultivar sensitivity to tuber necrosis caused by Tobacco rattle virus. Plant Disease, 2018, 102(7): 1376-1385 (doi: 10.1094/PDIS-12-17-1918-RE).

21. Minson T., Dabby G. 3'-terminal oligonucleotide fragments of tobacco rattle virus ribonucleic acids. Journal of Molecular Biology, 1973, 77(2): 337-340 (doi: 10.1016/0022-2836(73)90339-2).

22. Crosslin J.M., Hamm P.B., Kirk W.W., Hammond R.W. Complete genomic sequence of a Tobacco rattle virus isolate from Michigan-grown potatoes. Archives of Virology, 2010, 155(4): 621-625 (doi: 10.1007/s00705-010-0609-0).

23. Kim Y.J., Lim M.S., Kim S.M., Ryu K.H., Choi S.H. Molecular characterization of the Tobacco rattle virus RNA2 genome isolated from Gladiolus. Acta Biologica Hungarica, 2015, 66(2): 222-230 (doi: 10.1556/018.66.2015.2.8).

24. Игнатов А.Н. Необходимо усилить борьбу с бактериозами картофеля. Картофель и овощи, 2011, 5: 28-29.

25. Toth I.K., van der Wolf J.M., Saddler G., Lojkowska E., Hélias V., Pirhonen M., Tsror (Lakhim) L., Elphinstone J.G. Dickeya species: an emerging problem for potato production in Europe. Plant Pathology, 2011, 60(3): 385-399 (doi: 10.1111/j.1365-3059.2011.02427.x).

26. Shneider M.M., Kabanova A.P., Korzhenkov A.A., Miroshnikov K.K., Thi N.H.V., Toshchakov S.V., Miroshnikov K.A., Ignatov A.N. Draft genome sequence of Pectobacterium atrosepticum PB72 and complete genome sequence of the specific bacteriophage PP90. Genome Announcements, 2018, 6: e00473-18 (doi: 10.1128/genomeA.00473-18). 
27. Khayi S., Blin P., Chong T.M., Robic K., Chan K.-G., Faure D. Complete genome sequences of the plant pathogens Dickeya solani RNS 08.23.3.1.A and Dickeya dianthicola RNS04.9. Genome Announcements, 2018, 6: e01447-17 (doi: 10.1128/genomeA.01447-17).

28. Li X., Ma Y., Liang S., Tian Y., Yin S., Xie S., Xie H. Comparative genomics of 84 Pectobacterium genomes reveals the variations related to a pathogenic lifestyle. BMC Genomics, 2018, 19(1): 889 (doi: 10.1186/s12864-018-5269-6).

29. Ryazantsev D.Yu., Zavriev S.K. An efficient diagnostic method for the identification of potato viral pathogens. Molecular Biology, 2009, 43(3): 515-523 (doi: 10.1134/S0026893309030200).

30. Saitou N., Nei M. The neighbour-joining method: a new method for reconstructing phylogenetic trees. Molecular Biology and Evolution, 1987, 4(4): 406-425 (doi: 10.1093/oxfordjournals. molbev.a040454).

31. Bustin S.A., Benes V., Garson J.A., Hellemans J., Huggett J., Kubista M., Mueller R., Nolan T., Pfaffl M.W., Shipley G.L., Vandesompele J., Wittwer C.T. The MIQE guidelines: minimum information for publication of quantitative real-time PCR. Clinical Chemistry, 2009, 55(4): 611-622 (doi: 10.1373/clinchem.2008.112797).

32. Stakheev A.A., Ryazantsev D.Yu., Gagkaeva T.Yu., Zavriev S.K. PCR detection of Fusarium fungi with similar profiles of the produced mycotoxins. Food Control, 2011, 22(3-4): 462-468 (doi: 10.1016/j.foodcont.2010.09.028).

33. Stakheev A.A., Khairulina D.R., Zavriev S.K. Four-locus phylogeny of Fusarium avenaceum and related species and their species-specific identification based on partial phosphate permease gene sequences. International Journal of Food Microbiology, 2016, 225: 27-37 (doi: 10.1016/j.ijfoodmicro.2016.02.012).

34. Швидченко В.К., Хасанов В.Т., Фида М.А., Бейсембина Б., Харченко П.Н., Алексеев Я.И., Благодатских К.А., Казанцев А.С., Минакова Н.Ю. Сравнение методов иммуноферментного анализа и ПЦР в реальном времени для диагностики зараженности сортообразцов картофеля вирусами. Вестник Российской академии сельскохозяйственных наук, 2014, 2: 47-49.

35. Nie X., Singh R.R. Specific differentiation of recombinant PVYN:0 and PVYNTN isolates by multiplex RT-PCR. Journal of Virological Methods, 2003, 113(2): 69-77 (doi: 10.1016/S01660934(03)00221-0).

36. Potrykus M., Sledz W., Golanowska M., Slawiak M., Binek A., Motyka A., Zoledowska S., Czajkowski R., Lojkowska E. Simultaneous detection of major blackleg and soft rot bacterial pathogens in potato by multiplex polymerase chain reaction. Annals of Applied Biology, 2014, 165(3): 474-487 (doi: 10.1111/aab.12156).

37. Pritchard L., Humphris S., Saddler G.S., Parkinson N.M., Bertrand V., Elphinstone J.G., Toth I.K. Detection of phytopathogens of the genus Dickeya using PCR primer prediction pipeline for a draft bacterial genome sequences. Plant Pathology, 2013, 62(3): 587-596 (doi: 10.1111/j.1365-3059.2012.02678.x).

38. Zaczek-Moczydłowska M., Fleming C.C., Young G.K., Campbell K., O’Hanlon R. Pectobacterium and Dickeya species detected in vegetables in Northern Ireland. European Journal of Plant Pathology, 2019, 154(3): 635-647 (doi: 10.1007/s10658-019-01687-1).

39. Mumford R.A., Walsh K., Barker I., Boonham N. Detection of Potato mop top virus and Tobacco rattle virus using a multiplex real-time fluorescent reverse-transcription polymerase chain reaction assay. Phytopathology, 2000, 90(5): 448-453 (doi: 10.1094/PHYTO.2000.90.5.448).

40. Xu H., Nie J. Molecular detection and identification of potato isolates of Tobacco rattle virus. Canadian Journal of Plant Pathology, 2006, 28(2): 271-279 (doi: 10.1080/07060660609507296).

41. Holeva R., Philips M.S., Neilson R., Brown D.J.F., Young V., Boutsika K., Blok V.C. Realtime PCR detection and quantification of vector trichodorid nematodes and tobacco rattle virus. Molecular and Cellular Probes, 2006, 20(3-4): 203-211 (doi: 10.1016/j.mcp.2005.12.004).

ІФГБУН Институт биоорганической химии им. академиков М.М. Шемякина и Ю.А. Овчинникова РАН, 22 октября 2019 года Поступила в редакцию 117997 Россия, г. Москва, ул. Миклухо-Маклая, 16/10, e-mail: stakheev.aa@gmail.com $₫$, magyter@yandex.ru, szavriev@ibch.ru; 2ФГБНУ Всероссийский НИИ картофельного хозяйства им. А.Г. Лорха,

140051 Россия, Московская обл., Люберецкий р-н, п. Красково, ул. Лорха, 23, литера «В»,

e-mail: korenevo2000@mail.ru, i.shmyglya@mail.ru, varyuriy@yandex.ru, pavel_galushka@mail.ru 


\title{
DISTRIBUTED IN THE TERRITORY OF RUSSIA
}

\author{
A.A. Stakheev1, M.S. Chigareva1, A.I. Uskov², I.V. Shmyglya', Yu.A. Varitsev², \\ P.A. Galushka², S.K. Zavriev1
}

${ }^{1}$ Shemyakin-Ovchinnikov Institute of Bioorganic Chemistry RAS, 16/10, ul. Miklukho-Maklaya, Moscow, 117997 Russia, e-mail stakheev.aa@gmail.com ( $₫$ corresponding author), magyter@yandex.ru, szavriev@ibch.ru;

${ }^{2}$ Lorkh All-Russian Research Institute of Potato Farming, 23, ul. Lorkha, pos. Korenevo, Lyubertsy Region, Moscow Province, 140051 Russia, e-mail korenevo2000@mail.ru, i.shmyglya@mail.ru, varyuriy@yandex.ru, pavel_galushka@mail.ru ORCID:

Stakheev A.A. orcid.org/0000-0002-0732-5321

Chigareva M.S. orcid.org/0000-0002-2940-5410

Uskov A.I. orcid.org/0000-0003-1596-8359

Shmyglya I.V. orcid.org/0000-0002-4727-7141

Varitsev Yu.A. orcid.org/0000-0002-2329-7965

Galushka P.A. orcid.org/0000-0003-4680-9684

The authors declare no conflict of interests

Acknowledgements:

The article was prepared as part of the Federal Program for the Development of Agriculture of the Russian Federation for 2017-2025 (Sub-Program "Potato breeding and seed production").

Received October 22, 2019

doi: 10.15389 /agrobiology.2020.1.77eng

\section{Abstract}

Russia is among the largest potato producers in the world. According to statistics for 2018, the sown area of potatoes amounted to 310.7 thousand ha, which is $3.5 \%$ more than in 2017 , and the gross harvest in the industrial sector is 7157 thousand tons. At the same time, potatoes are susceptible to infection by various plant pathogens of different taxonomic groups. In modern potato growing, the progressive spread of viral and bacterial diseases, which, in addition to reducing the yield, causes a catastrophic deterioration of tubers' quality, leads to a serious problem for commercial production. Not all dangerous pathogens belong to quarantine organisms in Russia. However, the need for their accurate and highly specific identification is not less than for quarantine organisms. Currently, classic diagnostic methods in potato growing are indicator plants, serological and cytological tests. They are relatively reliable, but not always sensitive enough, time-consuming and their use requires highly qualified personnel. A modern alternative to these methods are diagnostic systems based on polymerase chain reaction (PCR), in particular, its real-time modification (quantitative PCR, qPCR). In the present study, for the first time in Russia, qPCR-based tests were developed for six non-quarantine pathogens - necrotic strains of potato virus $\mathrm{Y}$ (PVYN-NTN and $\mathrm{PVY}^{\mathrm{N}: O}$ ), tobacco rattle virus (TRV), and pathogenic bacteria Dickeya solani, D. dianthicola, and Pectobacterium atrosepticum. Primers and fluorescent-labeled probes were designed based on nucleotide sequences presented in the NCBI GenBank international database for the amplicon size not more than $500 \mathrm{bp}$. The specificity of the proposed systems was shown in tests with the genetic material of pathogens that infect potatoes, which are taxonomically close or occupy similar ecological niches, such as the ordinary strain PVY, potato mop-top virus, Pectobacterium carotovorum, and $D$. zeae. The quality of the proposed test systems was also evaluated using plant material, presumably infected with the analyzed pathogens. Nucleic acids were isolated using Proba-NK (for RNA) and Proba-GS (for DNA) reagents (AgroDiagnostica LLC, Russia). For the reverse transcription reaction, the RevertAid Premium First Strand cDNA Synthesis Kit (Thermo Scientific, USA) was used. PCR was carried out in the Tertsik amplifier (DNA-technology, Russia), and quantitative PCR was performed in the DT-96 detection amplifier (DNA-technology, Russia). To assess possible inhibition, an internal control sample (IC, a plasmid with a specific $560 \mathrm{bp}$ insert) was added to the reaction mixture. Positive control samples (PCs) were cloned using the Quick-TA kit (Evrogen, Russia). Plasmid DNA concentration was determined (a NanoVue spectrophotometer, GE HealthCare, USA). DNA molecules were sequenced (an ABI PRISM 3730 automated sequencer, Applied Biosystems, USA). Analytical sensitivity was evaluated by quantitative PCR, in which sequential 10 -fold dilutions of plasmid DNA (PC in four independent replicates) in the range of $10^{7}$ to $10^{0}$ copies per reaction were used as matrices. High sensitivity of the developed test systems, ranging from 10 to 500 copies of specific DNA per reaction, as well as high reproducibility $(C v 1.5-2.0 \%)$ were shown. The maximum fluorescence increase for the developed hydrolyzed probes ranged from 1200 to 2000 units of background. The universality of the proposed amplification profiles can serve as the basis for adapting test systems to the multiplex PCR format. The obtained results indicate that these systems detect the analyzed pathogens with high specificity and sensitivity and can be used as part of phytosanitary control and routine diagnosis of 6 non-quarantine pathogens in plants, planting material and food products.

Keywords: diagnostics, quantitative PCR, sensitivity, specificity, Pectobacterium atrosepticum, Dickeya solani, Dickeya dianthicola, necrotic strains of potato virus Y, PVY, tobacco rattle virus. 